\title{
Whose life is it anyway? Capacity and consent in Canada
}

A wise patient will have a discussion with his or her family physician about personal-care directives. Wise hospital physicians will ask their patients about such directives at the time of admission. Unfortunately, such wisdom does not usually prevail. And given the broadly divergent capacity and consent legislation in Canada, the result is widely inconsistent approaches, as illustrated by these 2 cases.

Case I - a patient in Ontario: Joyce Holland, an elderly Toronto woman with advanced dementia, lacked the capacity to make decisions about her personal care and required total care at a long-term care facility. She was admitted to hospital with aspiration pneumonia, followed by repeated admissions to the intensive care unit (ICU). Eventually, the ICU team convened a family meeting and recommended that Mrs. Holland not be readmitted to the ICU and be discharged from hospital because of her slim chance of survival and the pain and suffering that can occur as a result of aggressive ICU treatments. Mrs. Holland's daughters said this wasn't what their mother wanted; however, they had nothing in writing to indicate Mrs. Holland's wishes. An ICU physician, Dr. Laura Hawryluck, sought an order from Ontario's Consent and Capacity Board (an independent body that conducts hearings into questions about medical decision-making) authorizing her to withhold life-sustaining treatment from Mrs. Holland. The board directed the daughters to permit "the nonprovision or withdrawal of ventilator support." ${ }^{1}$ The family appealed the decision with the Superior Court of Ontario, which ultimately released the daughters from the board's order, not because one approach was more ethical than the other, but because the board had misunderstood the medical evidence. Mrs. Holland's daughters requested that she continue to receive full medical care, including life-sustaining treatments. This process, from the time of the family meeting to the court's decision, lasted about I year.

Case 2 - a patient in Alberta: Mrs. T, an elderly patient with a similar condition to that of Mrs. Holland, was admitted to an acute care hospital with aspiration pneumonia. Her condition deteriorated and an ICU consultation was requested to consider mechanical ventilation. Mrs. T did not have a personal directive outlining her wishes or designating a surrogate decision-maker. In Alberta, in urgent situations when the patient is unable to provide informed consent and no guardian has been appointed, the practice is to permit treatment if 2 independent physicians assess the patient and sign a certificate indicating that there is a need for treatment or investigation, but that the patient cannot consent to it. ${ }^{2}$ Within 90 minutes, the ICU physician, in consultation with the admitting physician, decided not to admit Mrs. T to the ICU because of the underlying severity of her condition and the poor prognosis. They subsequently informed Mrs. T's daughter of this decision and redirected care to focus on comfort. Mrs. T died several hours later.
These cases highlight the extremes within Canada's patchwork approach to capacity and consent legislation that result in different management approaches and challenge clinicians, patients and families.

What of the individuals who move from one Canadian jurisdiction to another? Alberta, for example, is experiencing an influx of people from eastern Canada. How many of these people are aware of the requirement to draft a personal directive to appoint a surrogate decision-maker? Such lack of awareness can result in a family either being prevented from making decisions or going to court to seek guardianship. We as physicians have a responsibility to ensure that patients know of capacity and consent concerns specific to their jurisdiction.

Physicians face a difficult challenge in determining appropriate end-of-life care for their patients. This can only be done by exploring a patient's wishes and expectations, which are best communicated by families and friends. The lack of legislation in Alberta to expressly authorize a patient's family members to provide substitute consent should not be used as a reason not to consult them. At a minimum, all legislation should be based on an explicit national standard mandating the inclusion of patients' families and caregivers in the decision-making process. In addition, consent legislation provides guidance on when physicians must seek consent to provide therapy; however, it varies in its guidance on whether physicians need to seek consent to withhold or withdraw treatment that is not medically indicated.

We at $C M A J$ believe that national debate on these issues is needed to ensure that all relevant stakeholders are heard. These extremes of care, foisted upon Canadians through poorly conceived provincial consent and capacity legislation, should be amended. Failing this, national standards could be tied to federal transfer payments. Canadians deserve equitable quality of care.

\section{Sharon Straus MD MSc}

Section Editor, Reviews, $C M A J$

Tom Stelfox MD PhD

Assistant Professor

Department of Critical Care

University of Calgary

Calgary, Alta.

With the Editorial-Writing Team (Paul C. Hébert MD MHSc, Matthew B. Stanbrook MD PhD, Barbara Sibbald BJ, Ken Flegel MDCM MSc, Noni MacDonald MD MSc and Amir Attaran LLB DPhil)

\section{REFERENCES}

I. Scardoniv. Hawryluck (2004), CanLII 34326 (ON S.C.).

2. College of Physicians and Surgeons of Alberta. Guidelines: competency assessment and surrogate decision making: responsibilities and roles of a physician. Edmonton: The College; 2002. Available: www.cpsa.ab.ca/publicationsresources /attachments_policies/Competency\%2oAssessment $\% 20$ and $\% 20$ Surrogate\%20 Decision\%20Making.pdf (accessed 2007 Oct I8). 